\title{
CREATING A LEARNING COMMUNITY AND BUILDING ENGAGEMENT IN ONLINE ENGINEERING COURSES USING ACTIVE LEARNING INSTRUCTIONAL PRACTICES AND EDTECH TOOLS
}

\section{Sarah Hoyt, ${ }^{*}$ N. David Theodore, \& Terry L. Alford}

School for Engineering of Matter, Transport and Energy, Arizona State University, PO Box 876106, Tempe, AZ 85287, USA

*Address all correspondence to: Sarah Hoyt, School for Engineering of Matter, Transport and Energy, Arizona State University, PO Box 876106, Tempe, AZ 85287, USA; Tel.: (+1) 480-727-9651; Fax: (+1) 480-727-9321, E-mail: shoyt3@asu.edu

Research widely agrees that student engagement can have positive impacts on student learning and achievement. Many institutions have adopted best practices designed to enhance engagement in the classroom in response to the growing research that supports these instructional best practices. Similarly, as online learning trends soar, universities are also beginning to explore what engagement means for the online learning community. Active learning has been translated to the digital platform, but with asynchronous sessions and activities, many wonder if substantial engagement and student achievement are possible to the same degree as they can be in face-to-face courses. In an attempt to begin addressing this question, this article examines how one engineering faculty member shifted his face-to-face course to a hybrid format while incorporating the same degree of active learning and engagement practices that were present in the ground format. This article will discuss how the course was shifted, what impacts were present for students, and the faculty's reflection on how the shift impacted his craft.

KEY WORDS: active learning, engagement, online learning, curriculum development, backward design model, hybrid classes, STEM learning, higher education, online STEM

\section{BACKGROUND}

\subsection{Shift to Online Learning}

Over the last several years, colleges and universities have seen a rise in online enrollment. Between 2016 and 2017, over 31\% of all students enrolled at a public 
institution were taking at least some online courses, if not exclusively enrolled in online classes (Lederman, 2018). There are numerous reasons why students choose a digital platform for learning over face-to-face (F2F) learning, so addressing those numerous reasons in one platform can be challenging. As educational institutions work to build out their courses and programs that are available online, they are rethinking online course design to meet those demands. Particularly, how will they create and foster student engagement and learning so that the online degree is just as robust and authentic as that in the ground classroom? Is it possible for best instructional practices to be implemented digitally? And finally, can faculty create rapport and positive working relationships with students and among students in order to yield a class experience that will prepare them not only for subsequent courses, but also for the working world beyond graduation?

\subsection{Active Learning and Engagement in Online Courses}

Research has shown the benefits of utilizing active learning strategies as a way to boost student engagement in the classroom (Freeman et al., 2014; Prince, 2004; Michael, 2006). While most research on active learning and engagement is with regard to F2F courses, many of the strategies that are used can be applied to the digital learning platform. Specifically, many educational technology (EdTech) resources exist today in an attempt to foster an online community within courses. Other EdTech tools address components of active learning and engagement-style learning such as formative feedback through the use of polling software, platforms designed for interactive slide sets, and online chat rooms designed to mimic small group discussion, to name a few (Poll Everywhere, 2020; PlayPosit, 2020; Yellowdig, 2020). In addition to these tools, studies have also shown that "professor presence" is a concern for online learning (Price et al., 2018). Specifically, students wonder if they will still have the same exposure to, or engagement with, an online professor as they would in a F2F course. This concern also has implications in the overall quality of the course content. Professor presence, as defined by Anderson et al. (2001), is "the design facilitation and direction of cognitive and social processes for the realization of personally meaningful and educationally worthwhile learning outcomes."

In addition to professor presence, teaching STEM courses online can be challenging. Finding technology or learning management system (LMS) platforms that support complex equations, lab exercises, and other aspects of STEM courses can be difficult and can dissuade faculty from attempting to migrate their course to an online platform (Chen et al., 2015). While authors Felder and Brent (2009) have provided sound instructional best practices for STEM design, their focus has been on F2F courses; although online learning attempts to mirror courses taught at the ground level, the differences between synchronous and asynchronous learning must not be ignored. What the aforementioned 
authors found was that, outside of delivery modality, active learning increases student achievement much more than traditional lecturing does (Felder and Brent, 2009).

\section{COURSE SHIFT PROCESS}

After participating in a faculty development program on active learning and student engagement, one engineering professor from a large southwestern university began implementing various instructional best practices he had learned into his F2F courses. When the school of engineering began to offer engineering courses and programs online, this professor made the decision to transition from F2F to online courses. One caveat to his transition included the creation of a hybrid class: one that would be primarily conducted through a digital platform but would still provide opportunities to meet in person several times throughout the semester.

The course selected for transition was an undergraduate 200-level materials science (MSE) course. As a foundational course, the purpose of the course is to introduce students to the basic concepts of materials science, particularly the relationship between structure processing-property performance and key terms students will need to utilize in subsequent MSE courses. Table 1 includes the 13 learning outcomes for the course.

The course followed a structural pattern to provide consistent expectations to aid in student success. The pattern included lectures in the form of videos with embedded questions. These were chunked to increase engagement, and PlayPosit (2020), described in full below, was the platform used to manage the videos and questions. Homework assignments were lecture-based and also derived from the e-book for the course. In addition to the formative assessment provided by the homework, four exams and one final exam were also utilized to assess the course. Recitations were conducted weekly through the virtual meeting platform ZOOM and included interactive learning activities and quizzes. Types of these assignments included Kahoot! (2020) activities, group worksheets, and quizzes.

To help with the transition process, this professor enlisted the help of the university's Global Outreach and Extended Education (GOEE) office, an instructional design team created to help faculty migrate course content to online platforms using pedagogical and curricular ideologies. The goal of the first meeting between the professor and the GOEE team was to create a schedule for the course migration task. Weekly meetings were also established to maintain open lines of communication and to measure and ensure progress. The GOEE team also employed the Backward Design Method (BDM) as the primary means of creating the scope and sequence of the course as it pertains to the assessment of the content (Wiggins and McTighe, 2005). The BDM begins by prioritizing the goals/ 
TABLE 1: Undergraduate MSE course learning outcomes

1. Understand the role of materials engineers in contemporary engineering practice

2. Understand the use and significance of families of materials, metals, polymers, ceramics, semiconductors, composites in contemporary engineering applications

3. Understand correlation of electronic structure and bonding of atoms to macroscopic properties

4. Understand crystal structure and geometry and correlation to macroscopic properties

5. Understand defects and correlation to properties such as diffusion and plastic deformation

6. Understand and use principles of electronic band structure to explain electronic properties of conducting, insulating, and semiconducting materials

7. Understand methods and significance of mechanical properties of materials, derived from tests such as tensile, creep, and fatigue tests

8. Understand use principles of phase diagrams to understand and predict microstructures and properties of materials

9. Understand the effects of structure and processing on properties and microstructure and hardening of steels

10. Understand the effects of structure and processing on properties and microstructure of commercial alloys

11. Understand structure-processing-property relationships in polymers and composites, including thermal properties, mechanical properties, and viscoelasticity

12. Understand structure-processing-property relationships in ceramics, including amorphous and crystalline materials used in both structural and electronic applications

13. Understand the nature of various types of composites and structure and property relationships in composite systems

objectives of the course as they pertain to the course outcomes and the Accreditation Board for Engineering and Technology, or ABET, standards. Once the scope was determined and prioritized, the evidence to measure the progress or mastery of the content was created; in other words, the modes of assessment and the frequency of each assessment were defined. The final step of the BDM was to build out the lessons and the course content that the professor would use to teach the objectives and course content. The BDM lends itself well to active learning and engagement-style teaching because it shifts the focus from content coverage to learning results by addressing the assessment ahead of the content creation.

After reviewing the current instructional materials and course content, the team and the professor modified the content as it related to the backward design model and the 
assessment that they had chosen to align. Because the professor had already begun employing active learning strategies in the F2F course, much of the original course content was migrated to the online course. One significant change, however, was with regard to the lecture material. The professor fragmented the lectures into more digestible chunks, and he also used the technology tool PlayPosit to embed questions into the lectures as a formative assessment to address any muddy points or common misconceptions of the material. An example of this EdTech tool is illustrated in Fig. 1.

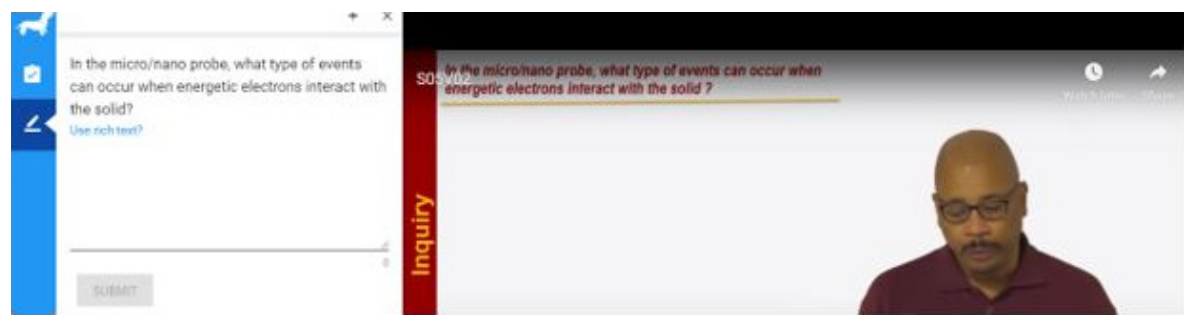

FIG. 1: Embedded question in chunked lecture for online engineering course

Another facet to the course's organization was that the material was organized into modules that contained the course content by week so that students could access materials chronologically. The first module, entitled Getting Started, was reserved as a repository for guidelines on how to navigate through the course and all of the new features for students. For example, instructions on how to use the LMS and some of the newer technology tools were inserted into this module. Similarly, this module contained activities designed to build community and student-to-student engagement through activities like introductions, discussions using the EdTech tool VoiceThread, and how to manage group assignments. Figure 2 shows an illustration of VoiceThread in use.

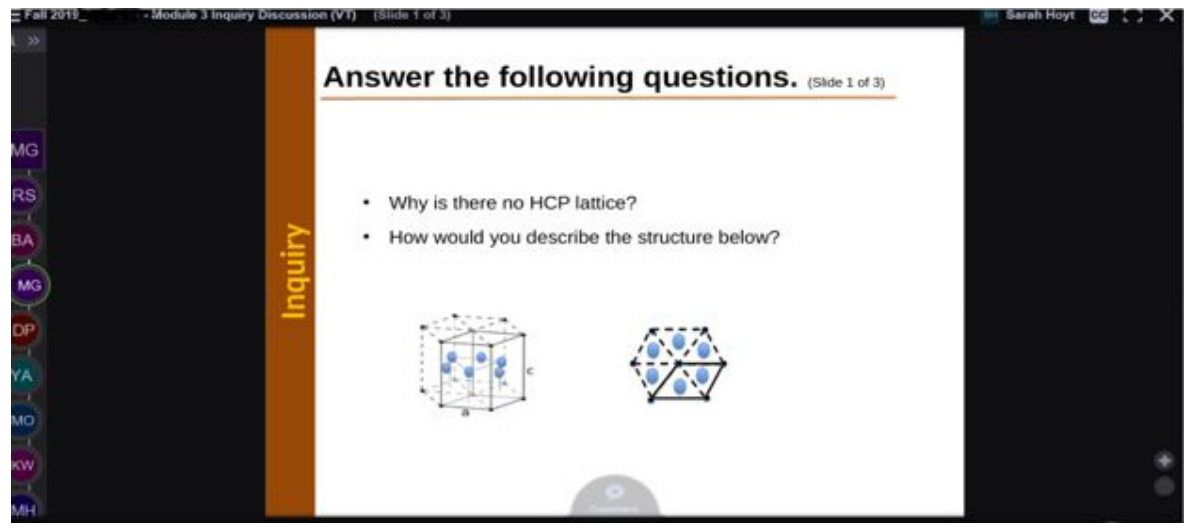

FIG. 2: VoiceThread sample with media and discussion forum

Once the course was built into the LMS, the team continued to meet to discuss what was implemented well and what needed to be modified, either within the same semester or for 
future classes. All of this information was recorded for subsequent review and reflection. One reflection that resulted in a change was the shift from a paper textbook to an e-book. This shift was made after the professor researched the benefits of an e-book, not only for time management purposes, but also for the succinctness with the LMS. Another benefit of an e-book's structure is that it provides numerical and concept questions on materials that are presented in the lectures. There is also an explanation section that effectively acts as a personal tutor for each student.

Aside from an academic perspective, the professor employed several activities and tools to create an online community. For example, each module contained a group homework assignment. The professor utilized the "Groups" feature within the LMS to facilitate these downloadable text assignments and provide each group with a "private" space to collaborate and complete each assignment. Another component of the course, "Tea with the Professor," was used to facilitate group projects. As a way to help students feel more comfortable with engaging with the professor, he required each student to bring a teacup to the session. The first question was about the teacup: students were to describe their cup and why they chose that particular cup as a virtual "icebreaker" before the topic shifted to course content or to discuss group dynamics. For the recitation portion of the course, the professor limited the number of students in each session to 25 , with the expectation that if students were "not heard or not seen," [they] "were not there." From there, the professor had subsequent "breakout" rooms for students to enter to discuss the problems for that recitation. Then, the students would reconvene as a larger group to discuss the problems and to take a short quiz to assess their understanding. Figure 3 illustrates the format of this type of virtual office hours.

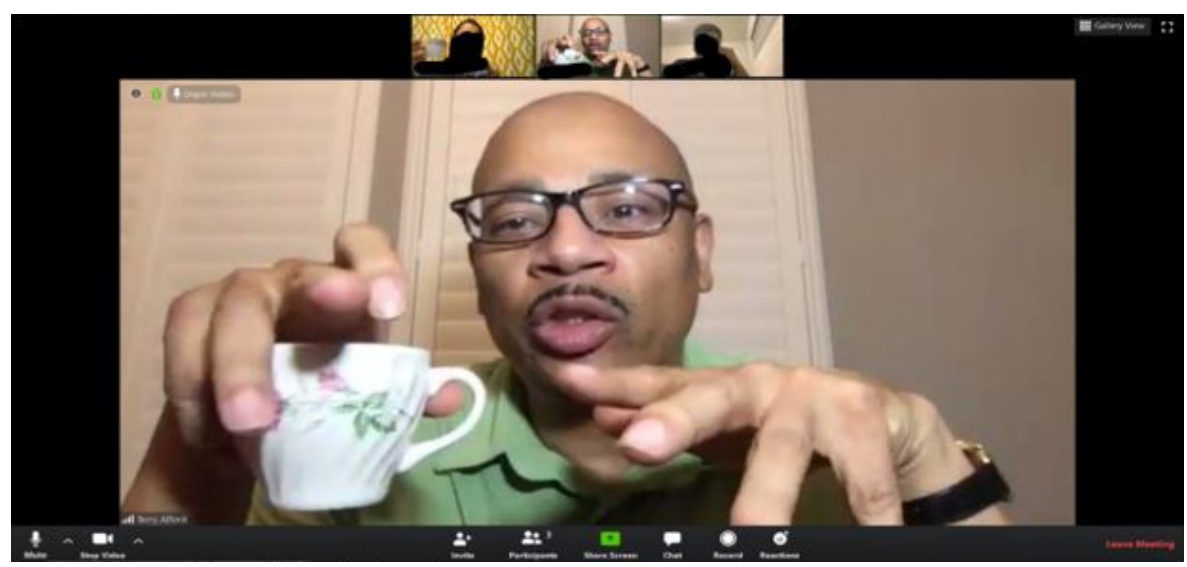

FIG. 3: Tea with the Professor screenshot 


\section{METHODS}

To measure student impact from an achievement standpoint, grade point averages (GPAs) were examined from the same course taught traditionally (e.g., "Sage on the Stage"), the F2F format with active learning, and the online format with active learning. The traditional format was designed around lecture-based classes where the instructor spent the majority of the class time lecturing and assigning homework to be done outside of class. The second class format included a modification of the original material. The lectures were segmented by active learning strategies like Think-Pair-Share and Muddiest Points for formative feedback (Lyman, 1981; Mosteller, 1989). The online course utilized a hybrid approach: the majority of the class and work was performed online while the main assessments were held F2F. The coursework for the online platform was organized using the BDM, and assessments were linked to course outcomes and learning objectives. This course also utilized a collection of e-books written by both instructors (Theodore and Alford, 2018). The same instructors were used to ensure that the content was uniform in each course. The sample size differed among the course platforms; the traditional F2F lecture course contained three sections and 143 students, the F2F active learning course contained two sections and 71 students, and the online active learning course contained only one section of 64 students.

\section{RESULTS}

For each average student grade, a 95\% confidence interval was constructed using the samples. After analyzing GPAs and grades of D, E, or Withdraw (DEW) rates for the aforementioned courses, the following results emerged: the online active learning course format yielded the highest average grade with a margin of error of \pm 7.3 . For the same group of students, the DEW rate was the lowest at $4.6 \%$. In the F2F active learning course, the average grade for the course was $84 \%$ with a DEW rate of $13 \%$. The traditional F2F course yielded the lowest average grade of 78.3 and the highest DEW rate at $40 \%$. The lowest course evaluation was obtained the for the F2F course format. Table 2 illustrates the aforementioned data.

While it is acknowledged that other factors can influence GPA and DEW rates, one should note that significant research supports the idea that active learning boosts student achievement and engagement (Freeman et al., 2014). Research also supports the idea that when a professor incorporates multiple opportunities for teacher-student and studentstudent interactions, student achievement is increased (Kim and Sax, 2009). 
TABLE 2: GPA and DEW rates for each course type

\begin{tabular}{|cccc|}
\hline & $\begin{array}{c}\text { Traditional } \\
\text { Lecture-Based } \\
\text { F2F }\end{array}$ & $\begin{array}{c}\text { F2F Active } \\
\text { Learning }\end{array}$ & $\begin{array}{c}\text { Online } \\
\text { Active } \\
\text { Learning }\end{array}$ \\
$\begin{array}{c}\text { No. of Sections } \\
\text { No. of } \\
\text { Students }\end{array}$ & 3 & 2 & 1 \\
Grade $\%$ & 143 & 71 & 64 \\
DEW & $48.3 \pm 7.4$ & $84.0 \pm 9.5$ & $86.5 \pm 7.3$ \\
$\begin{array}{c}\text { Lowest Course } \\
\text { Evaluation }\end{array}$ & $3.19 / 5.00$ & $4.31 / 5.00$ & $4.52 / 5.00$ \\
\hline
\end{tabular}

\section{FACULTY IMPACT}

While many studies focus solely on student impact, the authors of this article felt that it was important for the professor to provide some reflection on the process of course migration to a digital platform in terms of benefits and cost. The following reflection addresses the professor's attitudes on the main components of the online course.

It is often presumed that student interactions are very limited or nonexistent in online classes. However, with creative course design and the use of student engagement tools, the online interactions with students were equal to or greater than the F2F classes. These interactions were important aspects of building a community of learners (peer-to-peer), student-instructor engagement, asynchronous student-student engagement, and synchronous student-student engagement. Using tools such as VoiceThread, where students used a video response to a question or a set of questions, facilitated enhanced student interactions because their peers provided video replies to the original responses. The initial set of questions for the course was designed to be used as an icebreaker. The students introduced themselves, provided information about their educational background, employment history, and they answered one fun question. Another intent of this introduction was to provide an opportunity for students to self-organize into study groups and for collaborating on group homework assignments. This was also a great benefit for those students who did not have a materials engineering background or those who had been out of school for some time.

Another engagement consideration is engagement between the student and the instructor. Because the course was online, the office hours were held virtually, using the virtual meeting platform ZOOM Meeting. This allowed the instructor to conduct office hours at times that were more convenient for students who worked during the day or for those 
students in different time zones. In F2F office hours, a student would be able to leave the meeting with a hard copy of the problem discussed. With the aid of a digital whiteboard, the student was still able to receive a digital transcript of the problem or concept discussed, and they were also posted to the online course forum for all students to view. This was a benefit: once a professor realizes that more than one student is struggling with the same problem, he/she is able to post a clarification immediately to the entire class rather than having to wait for the next scheduled course meeting. The students reported that they valued having a digital transcript of the discussion or problem.

Similarly, the "Tea with the Professor" and the recitation components of the course worked really well at building community and engagement, not only between peers but also between the professor and students. The small breakout rooms during recitation also allowed for some individualized instruction and provided opportunities to engage with students on issues that pertained to their need and ability in the course.

Asynchronous student-student engagement was facilitated with subsequent VoiceThread questions and Muddiest Points on an electronic post-it platform, as illustrated in Fig. 4 below. The professor valued this method because students reported that they sometimes understood their peers more than the explanation offered by the professor. The professor also found that this method was extremely effective in addressing misconceptions. The added benefit of the asynchronous delivery of these misconceptions meant that the professor could catalog them on the electronic post-it boards for students to continue to reference as needed.

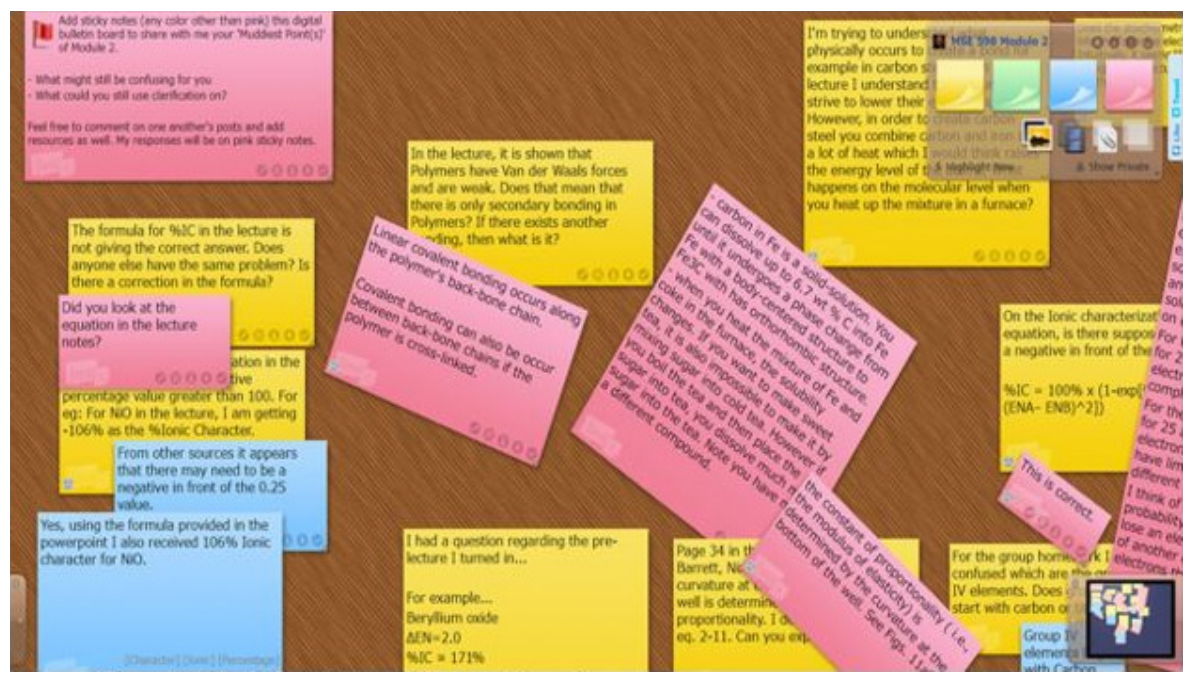

FIG. 4: Linoit Digital Post-It Platform example 


\section{CONCLUSION}

Shifting courses to an online platform still requires professors to incorporate sound pedagogical best practices in order to not only engage students but to also foster an environment that allows students to access the course content. The good news is that there are a myriad of EdTech tools to help facilitate active learning and engagement-style teaching in an online class. One key takeaway from this examination of course migration is that building a course with student-student and student-instructor interactions is essential for building and sustaining a learning community in the digital world. Another component essential to effective course migration is the use of an organizational model that utilizes student learning objectives and assessment as the vanguard for course design. Leading with those two components, as is done using the backward design model, provides instructors with an organized mode of content delivery that is focused on content learning rather than pacing or timing. Prioritizing content and building opportunities for students to engage with the material are the cornerstones of student performance and success in digital curricular design.

\section{REFERENCES}

Anderson, T., Rourke, L., Garrison, R., and Archer, W., Assessing Teaching Presence in a Computer Conferencing Context, J. Asynchronous Learning Networks, vol. 5, pp. 1-17, 2001.

Chen, B., Howard, W., and Bastedo, K., STEM Online Education: How to Create a Successful Online Course, 21st Annual Online Learning Consortium Int. Conf., Orlando, FL, 2015.

Felder, R.M. and Brent, R., Active Learning: An Introduction, ASQ Higher Ed. Brief, vol. 2, no. 4, 2009.

Freeman, S., Eddy, S.L., McDonough, M., et al., Active Learning Increases Student Performance in Science, Engineering, and Mathematics, PNAS, vol. 111, pp. 8410-8415, 2014.

Kahoot!, accessed January 23, 2020, from https://kahoot.com/, 2020.

Kim, Y.K. and Sax, L.J., Student-Faculty Interaction in Research Universities: Differences by Student Gender, Race, Social Class, and First Generation Status, Res. Higher Ed., vol. 50, p. 437, 2009.

Lederman, D., New Data: Online Enrollments Grow, and Share of Overall Enrollment Grows Faster, Inside Higher Ed, accessed August 27, 2019, from https://www. insidehighered.com/digital-learning, 2018. 
Lyman, F., The Responsive Classroom Discussion: The Inclusion of all Students, Mainstreaming Digest, accessed from https://archive.org/stream/mdu-univarch-027524/ univarch-027524\#page/n119/mode/2up/search/lyman, 1981.

Michael, J., Where's the Evidence that Active Learning Works?, Adv. Physiol. Ed., vol. 30, pp. 159-167, 2006.

Mosteller, F., The "Muddiest Point in the Lecture" as a Feedback Device, Teaching Learning: J. Harvard-Danforth Center, vol. 3, pp. 10-21, 1989.

PlayPosit, accessed January 23, 2020, from https://go.playposit.com/, 2020.

Poll Everywhere, accessed January 23, 2020, from https://www.polleverywhere.com/, 2020.

Price, K., Price, J., and Hayes, D., Online Doctoral Students at a Faith-Based University: Concerns of Online Education, NET: eJ. Faith-Based Distance Learning, 2018.

Prince, M., Does Active Learning Work? A Review of the Research, J. Eng. Ed., vol. 93, pp. 223-231, 2004. DOI: 10.1002/j.2168-9830.2004.tb00809.x

Theodore, D. and Alford, T., Intro to Materials Science Books 1-7, Seattle: Amazon.com, 2018.

VoiceThread, accessed January 23, 2020, from https://voicethread.com/, 2019.

Wiggins, G. and McTighe, J., Understanding by Design, 2nd ed., Alexandria, VA: Association for Supervision and Curriculum Development, 2005.

Yellowdig, accessed January 23, 2020, from https://yellowdig.com/, 2020. 